\title{
The Red Cross in the tundra
}

The Red Cross has proved time and again that it has no racial, historical or cultural bounds and that its humanitarian principles and ideals hold true on all continents and at all latitudes. This is borne out yet again by the following account of Red Cross work.

The article below is adapted from a text that recently appeared in the Review of the Soviet Red Cross; a translation was sent to us, at our request, by the Alliance of Red Cross and Red Crescent Societies of the USSR, whom we thank warmly for their kind co-operation.

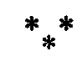

To enable the reader to fully appreciate the life and work of a Red Cross medical team and Red Cross volunteers beyond the polar circle, a brief description must be given of the region in which they carry out their activities.

The Autonomous Territory of Chukotska covers the north-eastern extremity of the Asian continent, which is also the north-eastern extremity of the USSR. It is a vast territory of 700,000 square kilometres straddling the polar circle. The ground is always frozen and for most of the year is covered with deep snow. Temperatures of minus $55^{\circ}$ centigrade and winds of around 180 kilometres an hour frequently prevail. The few inhabitants belong to various branches of the Eskimo and Asiatic-Siberian races. Some are nomadic and live from raising reindeer, great herds roaming the vast empty spaces of the tundra. Another group of the inhabitants are settled in the few localities of the territory, such as Anadyr, the capital, on the Bering Sea, or Pevek, on the coast of the Arctic Ocean. Before the use of motors and aircraft, it took six months of travelling with dog-sledges, to get from the one to the other. At the beginning of this century, the indigenous population of the region did 
not know how to write and had no written language. They had no idea of medicine and medical care; they were unceasingly threatened by isolation, hunger and disease.

Since then, within the space of two generations, the situation has considerably changed. The discovery of various minerals and their progressive exploitation, in spite of enormous difficulties due to the climate and the geographic situation, have contributed to the development of the territory and raised the living standard of the inhabitants. A mining industry has been established; new towns and villages have sprung up. Now, the town of Bilibin has a nuclear power station; the administrative capitale, Anadyr, has its own television studio and installations which allow it to receive and relay Moscow television broadcasts. Planes and helicopters are used for travel, in spite of the severe weather conditions. Education has made great progress: a high proportion $(70-80 \%)$ of the population not only know how to read and write but also have a good level of education.

The health service has also advanced rapidly. In 1924, the Ministry of Health and the Russian Red Cross sent the first medical missions to evaluate the health situation in the tundra and make the first plans to set up a local health service. Today, there are 257 health centres of various kinds in the territory, working to care for the sick, prevent epidemics and teach the population about health and hygiene. There are some 45 doctors, 127 nursing staff and 165 beds in medical establishments for 10,000 inhabitants. The central hospital has 305 beds and is divided into different sections (surgery, rheumatology, neurology, gyneacology, paediatrics, etc.). It can give up to $600-700$ out-patient consultations. In addition, the medical personnel make frequent rounds of the country, visiting even the most remote villages and the encampments of the reindeer-raising nomads of the tundra to provide medical examination and preventive care (inoculations and vaccinations). Planes and helicopters are available for use in emergencies.

All these achievements are due to the national health service. Faithful to its role as an auxiliary to the public authorities, the Red Cross, which has a branch in the autonomous territory, is simultaneously playing an important part in maintaining the health of the inhabitants, thanks to the work, intelligence and devotion of its volunteer members.

The Red Cross has recruited members in each collective farm, in the remote villages and the tent encampments of the reindeer herders. These are often women who, in addition to their domestic duties, are capable if need be of giving first aid to the wounded and caring for the sick, because they have been trained in first aid. As they are generally also 
responsible for maintaining radio contact with the neighbouring localities and encampments, and have to call them on schedule several times a day, they can if necessary consult a doctor long-distance and even ask him to come to the aid of the patient, depending upon the gravity of the case. Then planes or helicopters are evidently indispensable to cover the tremendous distances involved, braving the bad weather. Red Cross women volunteers also have the tasks of teaching young people what they themselves have learned of first aid, how to treat minor everyday injuries, how to prevent frostbire, not to drink water from dubious sources, how to bandage a cut or put on a splint...

Now that there are a lot of schools, children are taught first aid as well. First they are taught about personal hygiene and how to keep their dwellings clean; then they are progressively taught how to bandage a wound, stop a haemorrhage, set a fractured limb, and give first aid for frostbite. These courses are given by the school doctor and the Red Cross, and as an incentive for the children, competitions are held each year and prizes are awarded to the winners. When they grow up, these children will become members of Red Cross health centres, and of the teams of Red Cross volunteers which now meet in all localities and enterprises in the USSR. Of course, all these teams do the same work, with the same attention and the same devotion, but those living in the Autonomous Territory of Chukotska do so under extremely rigorous conditions, due to the climate and the great distances between one locality to another. Another serious difficulty that must be taken into account is that much of the population is in almost constant migration, following the herds of reindeer, and this precludes any continuity in care.

One proof of the success of Red Cross teaching is the voluntary donation of blood by the inhabitants of the tundra. Unknown a little while ago, the giving of blood has become commonplace, an evidence of the generosity, the strong feeling of solidarity and the devotion of the people of the far north in freely helping their neighbours. In the beginning, many of them could not give their blood because they suffered from certain diseases, but now, thanks to more widespread medical care, these difficulties have been eliminated. On 8 May, the annual Red Cross day, awards, medals and decorations are handed to deserving blood donors, as in other regions of the USSR. The result of all these efforts is remarkable: there are indigenous blood donors in all the rural districts of the autonomous territory, and the number of local donors is usually sufficient to meet the need for transfusions. In the town of Anadyr, 93 percent of the total quantity of blood used for transfusions is collected locally and free of charge. In view of the geographic situation, the living 
conditions and the climate of this region, these facts cannot be overemphasized.

Another Red Cross project which is successfully being carried out little by little is to give a wider public an elementary knowledge of hygiene and care of the sick. To do so, all women who have to spend a period of convalescence in hospital are given basic courses on home nursing. Their knowledge may subsequently prove useful to them, their families and their neighbours. Not only can they help an invalid to keep his house or tent clean and tidy and to prepare his food, but are also able to perform certain tasks prescribed by the doctor, for example, to change a bandage or apply a cupping glass or poultice. It is reckoned that over a twelvemonth period, in the Provideniya district alone, such simple training was given to around 700 persons.

Finally, mention must be made of another contribution by Red Cross volunteers. They are the people who take charge of cleaning roads, courtyards and public places in the townships, villages and encampments. In a territory where there is no highway department and where the inhabitants tend to be negligent, this is no small task and it contributes, perhaps as much as the doctors' work, to the prevention of epidemics. It is a fact that the region has not had an outbreak of infectious disease for several years, and this humble work carried out by Red Cross volunteers certainly has great social value.

Such a vigorous, active and efficient Red Cross, working in a remote area with a terrible climate and arduous living conditions, cannot but be admired. 